closer to the truth because $D$ is comparatively small.

In the simulations $w_{0}$ has been treated as empirical parameter. It is expected to be independent of temperature and field strength as long as the latter is high enough to justify the Boyle and Gabriel model despite of a finite zero-field splitting. Due to the zero-field splitting the level spacings are of course not really equidistant, but this may be compensated in part by an inhomogeneous broadening of the levels. For the spectra of the trinuclear complex recorded under 6.21 and $2.47 \mathrm{~T}$ it was indeed possible to get satisfactory simulations for the whole temperature range from 4.2 to $50 \mathrm{~K}$ with one single value for $w_{0}$. The zero-field splitting, rhombicity, and hyperfine parameters were taken as determined from the low-temperature spectra except that, for the sake of simplicity, the Euler angles $\alpha$ and $\beta$ of the efg tensor have been disregarded. The solid lines in Figure 8 show the simulations obtained for $S=3 / 2$ and the parameters of Table IV with $w_{0}=$ $2.6 \times 10^{8} \mathrm{~s}^{-1}$. The estimated uncertainty of this value is about $20 \%$.

The relaxation rate in the tetranuclear complex is obviously faster. The solid lines through the spectra in Figure 9 are simulations obtained for $S=3 / 2$ and the parameters of Table IV with $w_{0}=2.2 \times 10^{9} \mathrm{~s}^{-1}$. Direct comparison with the trinuclear complex is possible, since the applied field of $6.21 \mathrm{~T}$ is so strong that the spin $1 / 2$ of the monomeric $\mathrm{Cu}$ (Mesalen) is coupled in a kind of Paschen-Back effect much stronger to the external field than to the spin $3 / 2$ of the trimer. The monomer may, however, mediate the cross-relaxation between two trimers, thus enhancing the relaxation rate by about 1 order of magnitude. This finding is not unexpected because it is well-known, e.g. from the work of Bhargava et al., ${ }^{24}$ that the presence of other paramagnetic ions shortens the spin-spin relaxation times substantially. Such an explanation is also consistent with the $\mathrm{X}$-ray structure of the crystalline tetranuclear entity described in the preceding section.

Acknowledgment. This research was supported in part by NATO Research Grant No. 330/87.

Supplementary Material Available: Tables S1 and S2, listing interatomic distances and bond angles for the $\mathrm{PF}_{6}$ anions and anisotropic thermal parameters (2 pages); a listing of observed and calculated structure factors (19 pages). Ordering information is given on any current masthead page.

(24) Bhargava, S. C.; Knudsen, J. E.; Morup, S. J. Phys. Chem. Solids 1979, 40,45 .

Contribution from the Departments of Chemistry, Loyola University of Chicago, Chicago, Illinois 60626, and University of Coimbra, 3000 Coimbra, Portugal, and Laboratory of Organic Chemistry, Delft University of Technology, Julianalaan 136, 2628 BL Delft, The Netherlands

\title{
Multinuclear NMR Study of the Interaction of the Shift Reagent Lanthanide(III) Bis(triphosphate) with Alkali-Metal Ions in Aqueous Solution and in the Solid State ${ }^{\dagger}$
}

\author{
Ravichandran Ramasamy, $\$, 8$ Duarte Mota de Freitas, ${ }^{*, \neq}$ Carlos F. G. C. Geraldes," and Joop A. Peters ${ }^{*, \perp}$ \\ Received January 4, 1991 \\ The paramagnetic ion-induced relaxation rate enhancements of ${ }^{6} \mathrm{Li}$ in adducts of $\mathrm{Li}^{+}$and $\mathrm{Ln}(\mathrm{PPP}){ }_{2}{ }^{7-}$ complexes $(\mathrm{Ln}=\mathrm{Dy}, \mathrm{Tm})$ \\ in aqueous solution show that up to seven monovalent counterions can coordinate in the second coordination sphere of the $\operatorname{Ln}$ (III) \\ ion to the outer oxygens of the triphosphate ligands. However, the pseudocontact ${ }^{7} \mathrm{Li}$ NMR shift data suggest that in the second \\ coordination sphere some preference of the counterions for the axial region opposite the water ligand may exist. The estimated \\ $\mathrm{Ln}^{3+}-\mathrm{Li}^{+}$distances range from 5.1 to $5.9 \AA$ for $\left[\mathrm{Li}^{+}\right] /\left[\mathrm{Ln}(\mathrm{PPP})_{2}{ }^{7-}\right]$ ratios of $0.2-7$. This is supported by a two-dimensional nutation \\ spectrum of a polycrystalline sample of $\mathrm{Na}_{7} \mathrm{La}(\mathrm{PPP})_{2}$, which indicates coordination of all $\mathrm{Na}^{+}$ions to phosphate oxygens.
}

\section{Introduction}

Several aqueous shift reagents (SRs) for metal cation NMR spectroscopy have been reported. ${ }^{1-6}$ They have been shown to be useful in membrane transport biochemistry, for example in studies of alkali-metal ion transport across vesicles ${ }^{7,8}$ and red blood cell membranes. . $^{1.9-12}$ However, only two of them, Dy(TTHA) ${ }^{3-}$ and $\operatorname{Tm}(D O T P)^{5-}$, have found useful practical application for perfused heart studies ${ }^{13,14}$ and in vivo rat brain ${ }^{23} \mathrm{Na} \mathrm{NMR}$ spectroscopy. ${ }^{15,16}$ Despite considerable discussion, there seems still to be some controversy regarding the mode of interaction of one of the SRs most widely used for NMR studies in cell systems, namely Dy(PPP) ${ }_{2}{ }^{7-}$, with alkali-metal ions in aqueous solution..$^{17-23}$ Moreover, it has been shown recently that $\mathrm{Dy}(\mathrm{PPP}){ }_{2}{ }^{7-}$ can change ion distribution and transport across red blood cell membranes as well as membrane potential. ${ }^{24,25}$ These effects may be related to the mode of binding of alkali metal cations to Dy(PPP $)_{2}{ }^{7-}$. In

\footnotetext{
Authors to whom correspondence should be addressed.

Abbreviations used in this paper are as follows: PPPS-, tripolyphosphate: SRs, shift reagents; TTHA ${ }^{\sigma}$, tetraethylenetetraminehexaacetate; DOTP's-, tetraazacyclododecane- $N, N^{\prime}, N^{\prime \prime}, N^{\prime \prime \prime}$-tetrakis(methanephosphonate); MAS, magic angle spinning; NMR, nuclear magnetic resonance; LnIRE, lanthanide-induced relaxation rate enhancement.

'Loyola University.

IPresent address: Department of Chemistry, University of Texas at Dallas, Richardson, TX 75083.

University of Coimbra.

$\perp$ Delft University of Technology.
}

this work we further analyze this problem by studying the ${ }^{6} \mathrm{Li}$ NMR spin-lattice relaxation times of Dy(PPP) ${ }_{2}{ }^{7-}$ and $\operatorname{Tm}(\mathrm{PPP})_{2}{ }^{7-}$

(1) Gupta, R. K.; Gupta, P. J. Magn. Reson. 1982, 47, 344.

(2) Pike, M. M.; Springer, C. S., Jr. J. Magn. Reson. 1982, 46, 348.

(3) Pike, M. M.; Yarmusch, D.; Balschi, J. A.; Lenkinski, R. E.; Springer, C. S., Jr. Inorg. Chem. 1983, 22, 2388.

(4) Sherry, A. D.; Malloy, C. R.; Jeffrey, F. M. H.; Cacheris, W. P.; Geraldes, C. F. G. C. J. Magn. Reson. 1988, 76, 528.

(5) Buster, D. C.; Castro, M. M. C. A.; Geraldes, C. F. G. C.; Malloy, C. R.; Sherry, A. D.; Siemers, T. C. Magn. Reson. Med. 1990, 13, 239.

(6) Szklaruk, J.; Marecek, J. F.; Springer, A. L.; Springer, C. S., Jr. Inorg. Chem. 1990, 29, 660.

(7) Pike, M. M.; Simon, S. R.; Balschi, J. A.; Springer, C. S., Jr. Proc. Natl. Acad. Sci. U.S.A. 1982, 79, 810.

(8) Shinar, H.; Navon, G. J. Am. Chem. Soc. 1986, 108, 5005.

(9) Brophy, P. J.; Hayer, M. K.; Riddell, F. G. Biochem. J. 1983, 210, 961.

(10) Ogino, T.; Shulman, G. I.; Avison, M. J.; Gullans, S. R.; den Hollander, J. A.; Shulman, R. G. Proc. Natl. Acad. Sci. U.S.A. 1985, 82, 1099.

(11) Espanol, M. C.; Mota de Freitas, D. Inorg. Chem. 1987, 26, 4356.

(12) Pettegrew, J. W.; Post, J. F. M.; Panchalingam, K.; Whiters, G. Woessner, D. E. J. Magn. Reson. 1987, 71, 504.

(13) Pike, M. M.; Frazer, J. C.; Dedrick, D. F.; Ingwall, J. S.; Allen, P. D.; Springer, C. S., Jr.; Smith, T. W. Biophys. J. 1985, 48, 159.

(14) Malloy, C. R.; Buster, D. C.; Castro, M. M. C. A.; Geraldes, C. F. G. C.; Jeffrey, F. M. H.; Sherry, A. D. Magn. Reson. Med. 1990, 15, 33

(15) Albert, M. S.; Lee, J.-H.; Springer, C. S., Jr. Abstracts, 9th Annual Meeting of the Society of Magnetic Resonance in Medicine, New York, NY, 1990; p 1269.

(16) Naritomi, H.; Kanashiro, M.; Sasaki, M.; Kuribayashi, Y.; Sawada, T. Biophys. J. 1987, 52,611.

(17) Chu, S. C.; Pike, M. M.; Fossel, E. T.; Smith, T. W.; Balschi, J. A. Springer, C. S., Jr. J. Magn. Reson. 1984, 56, 33

(18) Nieuwenhuizen, M. S.; Peters, J. A.; Sinnema, A.; Kieboom, A. P. G.; van Bekkum, H. J. Am. Chem. Soc. 1985, 107, 12 . 
in sodium-free solutions containing increasing amounts of $\mathrm{LiCl}$. We also studied by solid-state MAS ${ }^{23} \mathrm{Na}$ NMR spectroscopy the interaction of $\mathrm{Na}^{+}$ions with $\mathrm{La}(\mathrm{PPP})_{2}{ }^{7-}$.

\section{Methods and Materials}

$\mathrm{DyCl}_{3}, \mathrm{TmCl}_{3}, \mathrm{D}_{2} \mathrm{O}$, and sodium triphosphate were obtained from Aldrich Chemical $\mathrm{Co} .{ }^{6} \mathrm{LiCl}\left(95.7 \%{ }^{6} \mathrm{Li}\right)$ was from Oak Ridge National Laboratories, TN. All chemicals were used as obtained, except sodium triphosphate, which was purified by repetitive precipitation from $33 \%$ aqueous ethanol. ${ }^{26}$ The purity of the resulting product was established by ${ }^{31}$ P NMR spectroscopy.

Tetramethylammonium triphosphate was prepared from the sodium form by ion-exchange chromatography and recrystallized as described earlier. ${ }^{21}$ The residual sodium content in crystallized tetramethylammonium triphosphate was analyzed by atomic absorption and ${ }^{23} \mathrm{Na}$ NMR spectroscopy and was found to be $2 \%$. ${ }^{31} \mathrm{P}$ NMR analysis of the above solution did not show any (phosphorous containing) impurities.

The shift reagents $\mathrm{Dy}(\mathrm{PPP})_{2}{ }^{7-}$ and $\mathrm{Tm}(\mathrm{PPP})_{2}{ }^{7-}$ were prepared as reported earlier. ${ }^{1}$ The ratio of $\mathrm{Dy}^{3+}$ or $\mathrm{Tm}^{3+}$ to $\mathrm{PPP}^{5-}$ was maintained at 1:2. In all samples the concentration of the shift agent was held constant at $5 \mathrm{mM}$ while ${ }^{6} \mathrm{LiCl}$ was varied between 1 and $100 \mathrm{mM}$. The $\mathrm{pH}$ of all samples was maintained at 7.5 and adjusted by using tetra. methylammonium hydroxide. No buffers were used. $\mathrm{pH}$ was checked before and after NMR measurements and was observed to be the same. $\mathrm{pH}$ values reported are not corrected for deuterium isotope effects. All the NMR samples had $15 \%(v / v) \mathrm{D}_{2} \mathrm{O}$.

The $\mathrm{Na}_{7} \mathrm{La}(\mathrm{PPP})_{2}$ salts were prepared by mixing a solution of $1 \mathrm{mmol}$ $\mathrm{LaCl}_{3} \cdot 6 \mathrm{H}_{2} \mathrm{O}$ in $5 \mathrm{~mL}$ of water with a solution of $2 \mathrm{mmol}$ of $\mathrm{Na}_{5}(\mathrm{PPP})$ in $5 \mathrm{~mL}$ of water. The solution was filtered and then poured into 100 $\mathrm{mL}$ of ethanol. The precipitate obtained was filtered off, washed with cold aqueous ethanol, and dried in the air.

${ }^{6} \mathrm{Li},{ }^{23} \mathrm{Na}$, and ${ }^{31} \mathrm{P}$ solution $\mathrm{NMR}$ measurements were made at 44.2 , 79.4 , and $121.4 \mathrm{MHz}$, respectively, on a Varian VXR-300 NMR spectrometer equipped with a $10-\mathrm{mm}$ multinuclear probe and a variabletemperature unit. ${ }^{6} \mathrm{Li} \mathrm{T}_{1}$ measurements were made by using the inversion-recovery pulse sequence. The errors in the reported $T_{1}$ measurements were less than $5 \%$. The spectral width was $8000 \mathrm{~Hz}$, and the probe temperature was $25^{\circ} \mathrm{C}$. For ${ }^{6} \mathrm{LiCl}$ concentrations lower than $20 \mathrm{mM}$, 256 scans were used, while for higher concentrations 64 scans were used in $T_{1}$ measurements.

The solid-state ${ }^{23} \mathrm{Na}$ NMR spectra were measured at $105.8 \mathrm{MHz}$ on a Varian VXR-400 S spectrometer equipped with a Doty solid-state probe. Magic angle spinning with a rate of about $6 \mathrm{kHz}$ was employed. The 2D-nutation spectra were recorded with $128 t_{1}$ increments of $2 \mu \mathrm{s}$. The if field strength was $60 \mathrm{kHz}$, which was determined by performing a nutation experiment with an aqueous solution of $\mathrm{NaCl}$. Note that the solid-state experiments were conducted on the $\mathrm{La}$ compound and not $\mathrm{Ln}$.

The speciations of species needed for the simulations of the curves of $R_{1}$ as function of $\rho$ were computed with the use of a Lotus 1-2-3 program. ${ }^{27}$

\section{Results and Discussion}

${ }^{6} \mathbf{L i}$ Spin-Lattice Relaxation Studies in Solution. For most alkali-metal ions the quadrupolar mechanism dominates the relaxation. ${ }^{28}$ As a result the relaxation rates are usually so high that pertubations by paramagnetic ions are hard to measure accurately. ${ }^{18}$ The ${ }^{6} \mathrm{Li}$ nucleus, however, has a very small quadrupole moment, and consequently its relaxation is extremely slow. ${ }^{28,29}$ Therefore, ${ }^{6} \mathrm{Li}$ is a very suitable probe for studying the location

(19) Anson, S. M.; Homer, R. B.; Belton, P. S. Inorg. Chim. Acta 1987, 138 , 241.

(20) Peters, J. A.; Sinnema, A.; Kieboom, A. P. G.; van Bekkum, H. Inorg. Chim. Acta 1989, $160,7$.

(21) Ramasamy, R.; Espanol, M. C.; Long, K. M.; Geraldes, C. F. G. C.; Mota de Freitas, D. Inorg. Chim. Acto 1989, 163, 41.

(22) Chu, S. C.-K.; Qui, H. Z.-H.; Springer, C. S., Jr.; Wishnia, A. J. Magn. Reson. 1990, 87, 287.

(23) Gupta, R. K. NMR Speciroscopy of Cells and Organisms: CRC Press: Boca Raton, FL, 1987; Vol. II, Chapter 7.

(24) Mota de Freitas, D.; Espanol, M. C.; Ramasamy, R.; Labotka, R. J. Inorg. Chem. 1990, 29, 3972.

(25) Ramasamy, R.; Mota de Freitas, D.; Jones, W.; Wezeman, F.; Labotka, R.; Geraldes, C. F. G. C. Inorg. Chem. 1990, 29, 3979.

(26) Quimby, O. T. J. Phys. Chem. 1954, 58, 603.

(27) van Westrenen, J.; Khizhnyak, P. L.; Choppin, G. R. Comp. Chem. submitted for publication.

(28) Akitt, J. W. In Multinuclear NMR; Mason, J., Ed.; Plenum Press: New York, 1987; $p 190$

(29) $\mathrm{LiCl}$ in $\mathrm{D}_{2} \mathrm{O}: T_{1}=887 \mathrm{~s}$. From previous data, ${ }^{18}$ the $T_{1}$ value of $\mathrm{La}(\mathrm{PPP})_{2} \mathrm{Li}_{7}$ is estimated to be about $20 \mathrm{~s}$.
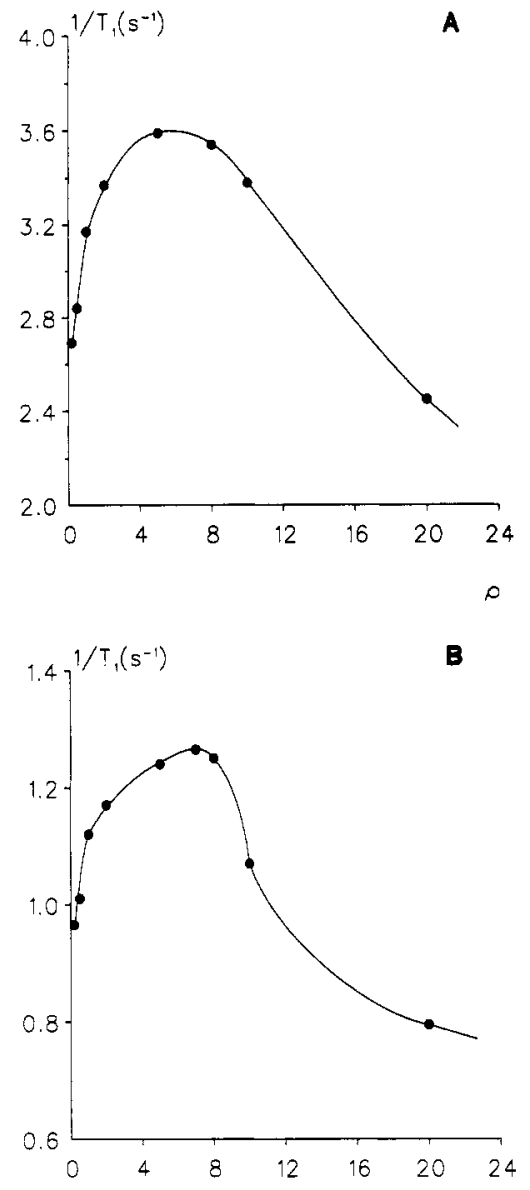

Figure 1. Spin-lattice relaxation rates of ${ }^{6} \mathrm{Li}$ in the presence of the $\mathrm{SRs}$ $\operatorname{Ln}(\mathrm{PPP}) 2_{2}{ }^{7-}(\mathrm{A}, \mathrm{Ln}=\mathrm{Dy} ; \mathrm{B}, \mathrm{Ln}=\mathrm{Tm})$, at $25^{\circ} \mathrm{C}$ and $\mathrm{pH}$ 7.5. The SRs were used in the tetramethylammonium form. The $\operatorname{Ln}(\mathrm{PPP})_{2}$ concentration was held constant at $5 \mathrm{mM}$, whereas the $\mathrm{Li}^{+}$concentration was varied between 1 and $100 \mathrm{mM}$ by addition of ${ }^{6} \mathrm{LiCl}$.

of counterions of negatively charged Ln(III) complexes via the lanthanide-induced relaxation rate enhancements (LnIRE). ${ }^{18,30}$

Figure 1 shows the variation of the measured ${ }^{6} \mathrm{Li}$ spin-lattice relaxation rate of $\mathrm{Na}^{+}$-free $5 \mathrm{mM}$ solutions of $\mathrm{Dy}(\mathrm{PPP})_{2}{ }^{7-}$ or $\mathrm{Tm}(\mathrm{PPP}){ }_{2}{ }^{7-} \mathrm{SRs}$ at $25^{\circ} \mathrm{C}$ and $\mathrm{pH} 7.5$ when the concentration of $\mathrm{LiCl}$ present varied from 1.0 to $100 \mathrm{mM}$ (the value of $\rho=$ $\left[\mathrm{Li}^{+}\right] /[\mathrm{SR}]$ changed from 0.2 to 20 ). The exchange rate between free and the various forms of SR-bound ${ }^{6} \mathrm{Li}$ was fast on the ${ }^{6} \mathrm{Li}$ NMR time scale; only a single ${ }^{6} \mathrm{Li}$ resonance was observed, the chemical shift of which was dependent on $\rho^{21}$ The values of $1 / T_{1}$ $\left(=R_{1}\right)$ increase by about $30 \%$ when $\rho$ increases from 0.2 to 7 . After a maximum at $\rho=7, R_{1}$ decreases steadily, as a result of exchange of the fast relaxing bound ${ }^{6} \mathrm{Li}^{+}$nuclei with the slow relaxing ${ }^{6} \mathrm{Li}^{+}$nuclei in the bulk. The difference in magnitude of the relaxation rates for the $\mathrm{Dy}^{3+}$ and the $\mathrm{Tm}^{3+}$ complexes can be explained by the differences in electron spin relaxation times and effective magnetic moments of these lanthanides (see below).

Assuming that isotropic relaxation occurs, that the contact contribution to the LnIRE is negligible, ${ }^{31}$ the value of $R_{1}$ for ${ }^{6} \mathrm{Li}^{+}$ bound to a $\operatorname{Ln}(\mathrm{PPP})^{7-}$ complex can be related to the distance between the $\mathrm{Ln}$ (III) ion and the ${ }^{6} \mathrm{Li}$ ion by using the reduced Solomon-Bloembergen equation: ${ }^{32,33}$

$$
R_{1}=4 / 3\left(\mu_{0} / 4 \pi\right)^{2}\left(\mu^{2} \gamma^{2} \beta^{2} T_{1 \mathrm{e}} / r^{6}\right)
$$

(30) Dwek, R. D. Nuclear Magnetic Resonance in Biochemistry, Clarendon Press: Oxford, England, 1973; Section 9.4.

(31) Reuben, J.; Fiat, D. J. Chem. Phys. 1969, 51, 4918.

(32) Alsaadi, B. M.; Rossotti, F. J. C.; Williams, R. J. P. J. Chem. Soc. Dalton Trans. 1980, 2147.

(33) Alsaadi, B. M.; Rossotti, F. J. C.; Williams, R. J. P. J. Chem. Soc., Dalton Trans. 1980, 2151. 

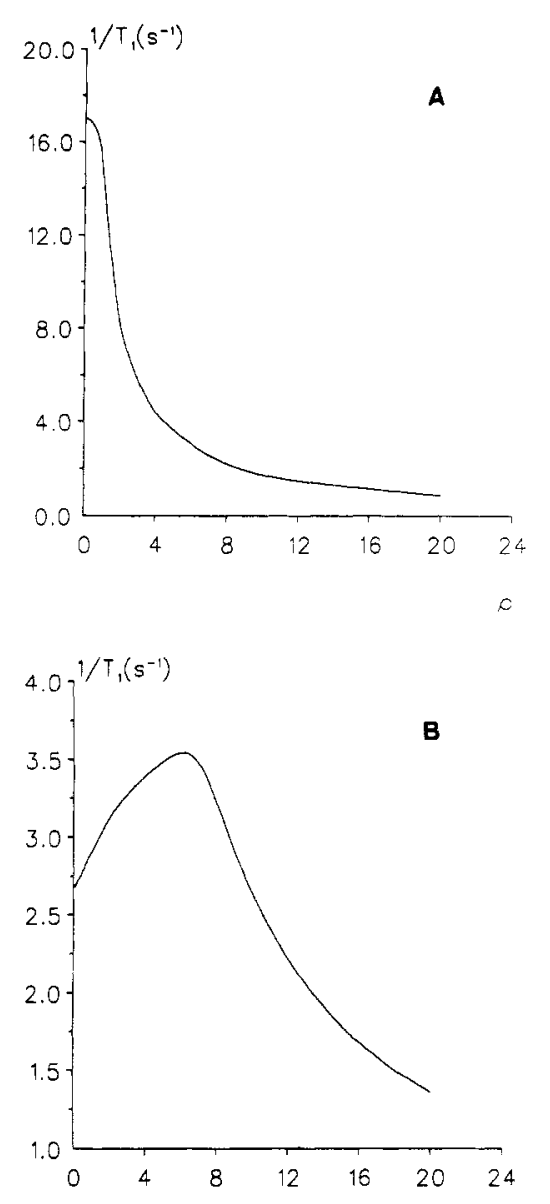

Figure 2. Simulated curves of ${ }^{6} \mathrm{Li}$ spin-lattice relaxation rates in the presence of a $\operatorname{Ln}(\mathrm{PPP})_{2}{ }^{7-}$ complex. (A) shows the model in which only one $\mathrm{Li}^{+}$binds strongly. Each triphosphate ligand is assumed to bind both $\mathrm{Ln}^{3+}$ and $\mathrm{Li}^{+}$ions. ${ }^{17,19,22,23}$ Parameters used are as follows: concentration $\mathrm{SR}=5 \mathrm{mM}$, stability constant adduct $K_{1}=10000 \mathrm{M}^{-1}, R_{1 \text { bound }}=17.4$ $\mathrm{s}^{-1}, R_{1 \text { free }}=0.05 \mathrm{~s}^{-1}$. (B) shows the model in which seven $\mathrm{Li}^{+}$ions are bound in the second coordination sphere of $\mathrm{Ln}^{3+}$ in the $\operatorname{Ln}(\mathrm{PPP})_{2}{ }^{7-}$ complex. Parameters used are as follows: concentration $\operatorname{Ln}(\mathrm{PPP}){ }^{7-}=$ $5 \mathrm{mM}$, stepwise stability constants $K_{1}=4000, K_{2}=2000, K_{3}=1800$, $K_{4}=1600, K_{5}=1400, K_{6}=1200, K_{7}=1000 \mathrm{M}^{-1}$. The corresponding $\mathrm{Li}^{+}$complexes are assumed to have the following $R_{1}$ values: $2.8,3.0,3.2$ $3.6,3.7$, and $3.8 \mathrm{~s}^{-1}$. For free $\mathrm{Li}^{+}$an $R_{1}$ value of 0.05 was assumed.

Here $\mu_{0} / 4 \pi$ is the magnetic permeability under vacuum, $\mu$ is the effective magnetic moment, $\gamma$ is the magnetogyric ratio, $\beta$ is the Bohr magneton, and $T_{1 \mathrm{e}}$ is the electron spin relaxation time. This latter parameter has been found to be rather independent of the ligation of the $\operatorname{Ln}$ (III) cation.32-34 If the adduct would have the previously suggested binuclear structure, in which each triphosphate is bound to both $\mathrm{Ln}^{3+}$ and $\mathrm{M}^{+}, 17,19,22,23$ the distance $\mathrm{Ln}^{3+}-\mathrm{Li}^{+}$would be about $4 \AA$. $^{23}$ Then for $\mathrm{Ln}=\mathrm{Tm}$, an $R_{1}$ value of $11.3 \mathrm{~s}^{-1}$ can be calculated with eq 1 and a $T_{1 \mathrm{e}}$ value of $4.6 \times$ $10^{-13} \mathrm{s.}^{32}$ Analogously it can be calculated that in the corresponding $\mathrm{LiDy}(\mathrm{PPP})_{2}{ }^{6-}$ system, the $R_{1}$ value of $\mathrm{Li}^{+}$is $17.3 \mathrm{~s}^{-1}$. These calculated relaxation rates are considerably larger than the experimental ones. The curves of $R_{1}$ as a function of $\rho$ were simulated with the use of the above-mentioned bound values of $R_{1}$, a value of $0.05 \mathrm{~s}^{-1}$ for free $\mathrm{Li}^{+},{ }^{29}$ and eq 2 , where $f_{\text {bound }}$ and

$$
R_{1}=f_{\text {bound }} R_{1 \text { bound }}+f_{\text {free }} R_{1 \text { free }}
$$

$f_{\text {free }}$ are the mole fractions of bound and free $\mathrm{Li}^{+}$, respectively, which were calculated by using a stability constant of the complex of $10000 \mathrm{M}^{-1}$. The calculated curves have shapes that differ dramatically from the experimental ones (see e.g. Figure $2 \mathrm{~A}$ ). The simulated curves show a steep decrease of $R_{1}$ at $p>1$, whereas

(34) Burns, P. D.; LaMar, G. N. J. Magn. Reson. 1982, 46, 61. the experimental ones have a maximum at $\rho$ about 7 . On the basis of these shapes and the lower $R_{1}$ values, the binuclear structure of the $\mathrm{Ln}(\mathrm{PPP})_{2}{ }^{7-}-\mathrm{Li}^{+}$adduct can be rejected. The experimental data strongly suggest that $\operatorname{Ln}(\mathrm{PPP}){ }_{2}{ }^{{ }^{-}}$complex binds rather strongly up to seven $\mathrm{Li}^{+}$ions in the second coordination sphere of the $\mathrm{Ln}^{3+}$ ion, which is in agreement with a previous proposal. ${ }^{18}$ The increase of $R_{1}$ between $\rho=0.2$ and 7 indicates that successive binding of the seven $\mathrm{Li}^{+}$ions to $\operatorname{Ln}(\mathrm{PPP})_{2}{ }^{7-}$ causes the $\mathrm{SR}-\mathrm{Li}_{n}$ structure to become more compact, probably as a result of the electrostatic repulsion between the ligands upon charge neutralization by the $\mathrm{Li}^{+}$ions. Simulation of the dependence of $R_{1}$ of $\rho$ for the $\mathrm{Dy}(\mathrm{PPP}){ }_{2}{ }^{7-}-\mathrm{Li}^{+}{ }_{n}$ adduct with a procedure similar to that described above, by using bound values for $R_{1}$ of 2.8-3.8 for $n=1-7$ and a somewhat arbitrary chosen set of stepwise stability constants for the respective adducts $\left(K_{n}=4000-1000 \mathrm{M}^{-1}\right)$, gives a curve that is in good agreement with the experimental one (see Figure 2B). A fitting of the experimental data with stability constants and relaxation rates was not attempted, since the model with seven bound alkali-metal ions requires 15 variables ( 7 stepwise stability constants and $8 R_{1}$ values). The good agreement between the experimental and simulated curve indicates, however, that the estimates of the bound $R_{1}$ values were correct. Then with eq 1 , it can be calculated that for the Dy(PPP ${ }_{2}{ }^{7-}-\mathrm{Li}^{+}{ }_{n}$ system the $\mathrm{Dy}^{3+}-\mathrm{Li}^{+}$distances vary between 5.4 and $5.1 \AA$, going from $n=$ 1 to 7. Analogously it can be calculated that in the $\operatorname{Tm}(\mathrm{PPP})_{2}{ }^{7-}$ system the $\mathrm{Tm}^{3+}-\mathrm{Li}^{+}$distance is between 5.9 and $5.7 \AA$. These distances show that the seven monovalent cations are coordinated to the outer oxygens of the triphosphate ligands.

It should be noted that the previously reported Dy(III)-induced ${ }^{7} \mathrm{Li}$ shifts of the $\mathrm{Li}^{+}-\mathrm{Dy}(\mathrm{PPP})_{2}{ }^{7-}$ system as a function of $\rho$ also showed a break at $\rho=7.21$ The induced shifts, however, decreased steeply between $\rho=0.2$ and 7 . If it is assumed that the induced ${ }^{7} \mathrm{Li}$ shifts are of a pseudocontact origin and that internal reorientations in the complexes result in effective axial symmetry, the induced shifts are determined by

$$
\Delta=k\left(3 \cos ^{2} \theta-1\right) / r^{3}
$$

where $\Delta$ is the induced shift and $\theta$ is the angle between the vector $r$ and the effective magnetic axis. The variation of the chemical shifts as function of $\rho$ indicates that at low $\rho$ values binding sites with a high $\Delta$ value are occupied by $\mathrm{Li}^{+}$preferentially. As outlined previously, ${ }^{18,20,21}$ the signs of the pseudocontact portion of the $\mathrm{Ln}(\mathrm{III})$-induced ${ }^{31} \mathrm{P}$ and ${ }^{17} \mathrm{O}$ shifts indicate that the triphosphate ligands are in the equatorial region $\left(55<\theta<125^{\circ}\right)$, whereas the water ligand is in the axial region $\left(0<\theta<55^{\circ}, 125<\theta<180^{\circ}\right)$ (see Figure 3). Similarly, the sign of the induced shift for the counterion nucleus indicates that the counterion also is located in the axial region. The coordination geometry of nine-coordinated $\mathrm{Ln}^{3+}$ complexes can often best be described by a tricapped trigonal prism. If it is assumed that this geometry also applies here, and if the binding fashion of the triphosphate ligands established previously ${ }^{18}$ is taken into account, a model can be constructed in which the water molecule and oxygens of the central phosphates of the triphosphate ligands occupy the capping positions and oxygens of the terminal phosphates the remaining positions (see Figure 3). Then the effective magnetic axis is most likely in the direction of the $\mathrm{Ln}^{3+}$-water bond, and the ${ }^{31} \mathrm{P}$ nuclei are indeed in the equatorial region. The crowding in the axial region opposite to the water ligand is relatively small, which may explain some preference of the counterions for this region.

Further addition of $\mathrm{Li}^{+}$leads to exchange of the $\mathrm{Li}^{+}$ions on this preferred site with those at other locations. Since each site has a different $\theta$ value, this will result in a decrease of the ${ }^{7} \mathrm{Li}$ shifts due to averaging of the $3 \cos ^{2} \theta-1$ term in eq 3 . In this way only one of the bound $\mathrm{Li}^{+}$ions contributes mostly toward the observed ${ }^{7} \mathrm{Li}$ shifts. The ${ }^{6} \mathrm{Li}$ relaxation measurements, however, unambiguously show that about seven monovalent counterions can be bound in the second coordination sphere of $\operatorname{Ln}(\mathrm{III})$ in the $\mathrm{Ln}$ (PPP $)_{2}{ }^{7-}$ complexes.

Solid-State ${ }^{23} \mathrm{Na} \mathrm{NMR}$ Studies of $\mathrm{Na}_{7} \mathrm{La}(\mathrm{PPP})_{2}$. In the solid-state MAS ${ }^{23} \mathrm{Na} \mathrm{NMR}$ spectrum of $\mathrm{Na}{ }_{7} \mathrm{La}(\mathrm{PPP})_{2}$ only a single broad line $\left(\Delta \nu_{1 / 2}=1.3 \mathrm{kHz}\right)$ was observed. The NMR spectra 


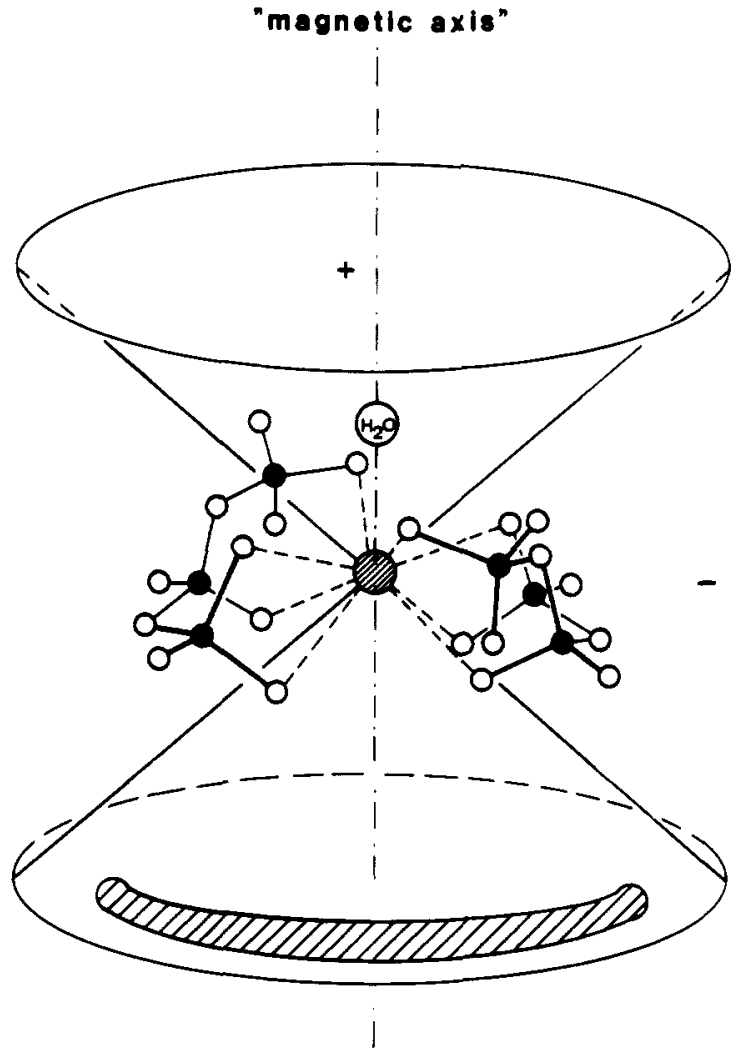

Figure 3. Schematic representation of the structure of the Ln(PPP) ${ }_{2}{ }^{7-}$-alkali-metal ion adduct. A tricapped trigonal-prismatic coordination of the $\mathrm{Ln}^{3+}$ ion is assumed. $-\mathrm{P}$, and $\mathrm{O}=0$.

of quadrupolar spin nuclei such as ${ }^{23} \mathrm{Na}(I=3 / 2)$ contain information on both the chemical shift and the quadrupole interaction, which depends on the local symmetry around the ${ }^{23} \mathrm{Na}$ nucleus, giving in principle direct information on the nature of the $\mathrm{Na}^{+}$sites. The two-dimensional solid-state nutation NMR spectrum allows one to separate the quadrupolar interaction from the chemical shift interaction. ${ }^{35-37}$ These spectra have been calculated theoretically for various half-integer quadrupolar spins, including $I=3 / 2.37$

Figure 4 shows the two-dimensional MAS ${ }^{23} \mathrm{Na}$ nutation spectrum obtained for a polycrystalline sample of $\mathrm{Na}_{7} \mathrm{La}(\mathrm{PPP})_{2}$. No separation is observed in the $F_{1}$ direction; only a single peak at $\left[2 \omega_{\mathrm{f},}, 0\right]$ is present. A comparison with simulated spectra ${ }^{37}$ shows that the absence of peaks at $\omega_{\mathrm{rf}}$ and between $\omega_{\mathrm{rf}}$ and $2 \omega_{\mathrm{rf}}$ indicates that all ${ }^{23} \mathrm{Na}$ nuclei have a nuclear quadrupolar coupling constant (QCC) of at least 1.4 MHz. This implies that in the solid state the seven ${ }^{23} \mathrm{Na}$ counterions are all in environments with high electric field gradients. These data, therefore, suggest that all

(35) Samoson, A.; Lippmaa, E. Chem. Phys, Lett. 1983, 100, 205.

(36) Samoson, A.; Lippmaa, A. Phys. Rev. 1983, B28, 6567.

(37) Kentgens, A. P. M.; Lemmens, J. J. M.; Geurts, F. M. M.; Veeman, W. S. J. Magn. Reson. 1987, 71,62 .

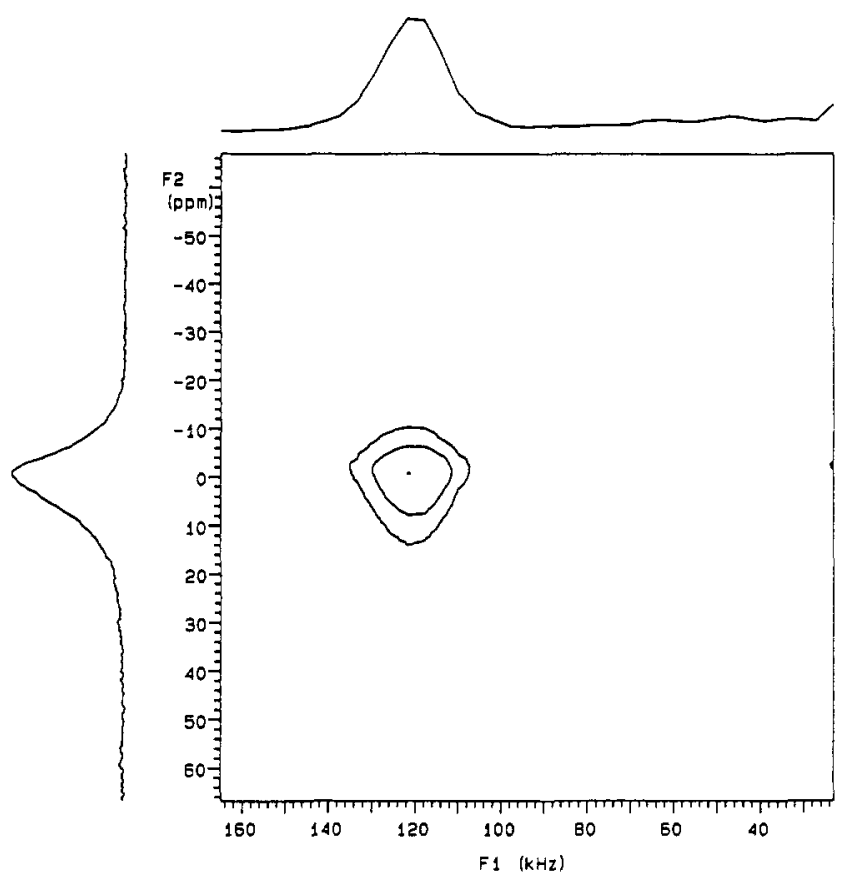

Figure 4. 2D nutation spectrum of $\mathrm{Na}_{7} \mathrm{La}(\mathrm{PPP})_{2}$ (contour plot), together with its projections on the $F_{1}$ and $F_{2}$ axis. The $2 \mathrm{D}$ spectrum contains information about chemical shift and quadrupole interactions along the $F_{2}$ axis and information exclusively about the quadrupole interactions along the $F_{1}$ axis. The of field strength used was $60 \mathrm{kHz}$.

$\mathrm{Na}^{+}$ions are coordinated to phosphates; for $\mathrm{Na}^{+}$ions with an octahedral coordination with water a lower QCC should be expected. It has, for instance, been reported that in a single crystal of $\mathrm{Na}_{4} \mathrm{P}_{2} \mathrm{O}_{7} \cdot 10 \mathrm{H}_{2} \mathrm{O}$ the $\mathrm{Na}^{+}$ions that are fully coordinated by water have a QCC of $0.467 \mathrm{MHz}$, whereas those coordinated to both waters and pyrophosphate have a QCC of $1.907 \mathrm{MHz}{ }^{38}$

The proposed coordination of seven $\mathrm{Na}^{+}$ions to the outer oxygens of the triphosphate ligand is supported by the crystal structure of $\mathrm{Na}_{5}(\mathrm{PPP}) \cdot 14 \mathrm{H}_{2} \mathrm{O}$, in which four of the five different $\mathrm{Na}^{+}$ions are coordinated to triphosphate oxygens. ${ }^{39}$

In conclusion, in both liquid and solid phases up to seven alkali-metal cations bind to the second coordination sphere of $\mathrm{Ln}$ (PPP) ${ }_{2}{ }^{7-}$ complexes via the outer oxygens of the triphosphate ligands (Figure 3 ) rather than having one preferential binding site in the proximity of the lanthanide ion. ${ }^{17,19,22,23}$ However, in the second coordination sphere some preference of the counterions for the axial region opposite the water ligand may exist.

Acknowledgment. C.F.G.C.G. acknowledges support from FLAD and INIC. Financial support from the National Institute of Mental Health (USPHS Grant 45926) is gratefully acknowledged by D.M.d.F. Thanks are due to J. Huskens for performing the simulations of the relaxation curves.

(38) Derbyshire, W.; Stuart, J. P. Proc. Colloq. AMPERE (At. Mol. Etud. Radio Elec.) 1968, 15, 403.

(39) Mootz, D.; Altenburg, H. Acta Crystallogr. 1969, B25, 1077. 